\title{
Hypoglycaemic Properties of Moringa oleifera Lam Seed Oil in Normoglycaemic Rats
}

\author{
${ }^{*}$ Busari M. B ${ }^{1}$., Muhammad H. L2., Ogbadoyi E. $\mathrm{O}^{1}$., Abdulrasheed-Adeleke, \\ $\mathrm{T}^{2}$., Sani, $\mathrm{S}^{3}$. \\ ${ }^{1}$ Centre for Genetic Engineering and Biotechnology, Global Institute for Bioexploration Unit, Federal \\ University of Technology, Minna Nigeria \\ ${ }^{2}$ Department of Biochemistry Federal University of Technology, Minna Nigeria \\ ${ }^{3}$ Department of Biochemistry Federal University Ndufu Alike Ikwo Abakaliki Ebonyi, Nigeria
}

\begin{abstract}
The healing properties of Moringa oil, also known as Behen oil, were documented by ancient and modern cultures. The hypoglycaemic properties of Moringa oleifera Lam seed oil extracted with petroleum ether and dichloromethane (MOPE and MODM) were investigated and compared with the standard drug glibenclimide (STND) in normoglycaemic rats. The oral doses of MOPE and MODM at 1.5, 2.0 and $2.5 \mathrm{ml} / \mathrm{kg}$ bodyweight along with $500 \mu \mathrm{g} / \mathrm{kg} . \mathrm{bw}$ STND and $2.5 \mathrm{ml} / \mathrm{kg} . \mathrm{bw}$ of dimethyl sulphoxide (DMSO) control group (CNTRL) respectively was given to 5 groups of normoglycaemic wister rats of 3 rats per group. MOPE $(2.0 \mathrm{ml} / \mathrm{kg} . \mathrm{bw})$ and $S T N D$ showed significant $(P<0.05)$ decrease in blood glucose at $120 \mathrm{mins}(14.10 \%$ and $14.79 \%)$ while MODM $(1.5 \mathrm{ml}$ and $2.0 \mathrm{ml})$ and $S T N D$ showed significant $(P<0.05)$ decrease in blood glucose level at $6.88 \%, 15.22 \%$ and $14.10 \%$ respectively. The acute toxicity test of MOPE and MODM showed no sign of toxicity at higher dose of $5 \mathrm{ml} / \mathrm{kg} . \mathrm{bw}$. Therefore, Moringa oleifera seed oil can serve as a source of potential hypoglycaemic agent or adjuvant.
\end{abstract}

Keywords: Normoglycaemic, glibenclimide, blood glucose, hypoglycaemic, Moringa oil.

\section{Introduction}

Almost 120 million people are currently suffer from diabetes mellitus globally and this figure is estimated to be doubled by the year 2025 (King et al., 1998). In reaction to this worldwide health confrontation, the WHO Expert Committee on diabetes mellitus suggested more evaluation of the folkloric methods of combating this disease in order to curb high death rate and morbidity that do occur from its complications as well as adverse effect connected with the use of modern antidiabetic drugs (Adeneye et al., 2006). In order to achieve this goal, the hypoglycaemic efficacies of several medicinal plants have been investigated. It has been generally observed that herbal formulations are more advantageous to modern therapy because of their low toxicity, easy accessibility, low cost and popularity.

Oil therapy and aroma therapy are well known to have been used in the treatment of various diseases in ancient and modern practice. Oil therapy is now being employed in the treatment of several diseases including diabetes. The hypoglycaemic effects of several seeds oil have been investigated in animal model by different researchers. Such oil include Nigella sativa (Mohtashami et al., 2011), Walnut oil (Parivash et al., 2011), Coconut oil (Mahadevappa, Arunchand and Farhath, 2011), Picralima nitida (Calistus and Vincent, 2011), Garlic oil (Cheng-Tzu Liu et al., 2005).

Moringa oleifera is the most popular among the 13 species of genus Moringa. It is commonly known by regional names as drumstick tree, kelor, murungai kaai, saijhan, benzolive among many names; it is a rapidly growing tree that is widely cultivated and has now become naturalized in Afghanistan, Florida and East and West Africa (Paliwal et al., 2011).The aqueous extract of Moringa oleifera leaf was reported to exhibit hypoglycaemic and antidiabetic effect in normal and streptozotocin-induced sub, mild and severely diabetic rats (Jaiswal, Kumar, Kumar, Mehta and Watal, 2009). Having affirmed the uses of some oil as hypoglycemic agents, it is therefore worthwhile to evaluate the hypoglycaemic effect of M.oleifera oil because of some of its immense medicinal values.

\subsection{Materials}

\section{Materials And Methods}

2.1.1 Plant materials: The dried pods of M. oleifera were collected from Bosso estate in Niger State Nigeria, Bosso Local Government Area, on June 2013. A taxonomic aid provided by Abdullahi et al. (2003) as well as Schippers (2000) was used to authenticate the plant materials by a Botanist in Biological Science Department, Federal University of Technology Minna, Niger State. The seeds were threshed from the pods, air dried, ground into powdered form, using a rotary blender, and stored for future use. 
2.1.2 Experimental animals: Wister rats of weight $140-180 \mathrm{~g}$ were used for the experiment. The animals were obtained from Biochemistry and Chemotherapy section of the National Institute for Trypanosomiasis and Onchocerciasis Research (NITR) Vom, Plateau State, Nigeria. The animals were adapted to the environment for two weeks prior to study in the Department of Biochemistry laboratory, Federal University of Technology, Minna. Internationally accepted principles for laboratory animal use and care as contained in the Canadian Council on Animal Care guidelines on animal use protocol review (1997) and as also described by Adamu et al. (2010) was followed during the uses of the animals.

2.1.3 Apparatus and reagents: The following reagents were used for the biochemical analysis: Alloxan monohydrate was a product of Qualikem, Fine Chem. Pvt. Ltd, Vadodara, India, Achu-chek glucometer and petroleum ether and Dichloromethane were from BDH chemicals.

\subsection{Methods}

2.2.1 Extraction of Moringa oleifera oil: About $50 \mathrm{~g}$ of pulverised M. oleifera seeds were placed into a cellulose paper cone and inserted into Soxhlets extractor fixed with a $500 \mathrm{ml}$ round-bottom flask and a condenser. The extraction was executed for about 8 hours with $300 \mathrm{ml}$ of petroleum ether and same process was adopted for dichloromethane extraction. The solvents were distilled out using rotary evaporator. The percentage oil yield was determined after the evaporation of solvents.

2.2.2 Determination of percentage oil yield: The average oil yield on each sample was obtained as follow;

$\%$ Oil Yield $=$ Weight of sample before extraction-Weight of sample after extraction $\times 100$

Weight of sample before extraction

2.2.3 Acute toxicity test: Acute oral toxicity of M. oleifera oil extract was determined using OECD guidelines. The limit test was adopted by given oral dose of $500 \mathrm{mg} / \mathrm{kg}$.bw to five female wister rats of body weight between $140-180 \mathrm{~g}$ after 16 hours of fasting. Animals were observed continuously up to $4 \mathrm{hrs}$, for detailed behavioural, autonomic and neurological profiles. Signs of delayed toxicity or mortality were monitored up to a period of fourteen days $(\mathrm{OECD}, 2008)$

2.2.4 Hypoglycaemic effects of petroleum ether and dichloromethane oil extract of Moringa oleifera seed (PEEMO and MODM) on normoglycemic rats: Doses of 1.5, 2.0 and 2.5ml $/ \mathrm{kg} . \mathrm{bw}$ of MOPE and MODM were given to normoglycaemic rat along with $500 \mu \mathrm{g} / \mathrm{kg}$.bw standard drug glibenclimide and placebo (2.5ml/kg.bw DMSO). The glucose was monitored at the baseline before the extract administration then at 30 , 60,90 and 120 mins after oral administration of the extracts.

2.2.5 Determination of blood glucose levels: Blood glucose level was determined using an Achu-check glucometer (Roche) via the tail snip of the animals at defined times in the experimental protocol.

\subsubsection{Animal Grouping and Treatments}

Hypoglycaemic effects of dichloromethane oil extract of Moringa oleifera (MODM) on normoglycaemic rats: The rats were divided into 5 groups comprising of 3 animals each $(n=3)$.

CNT: Normoglycaemic rats received $2.5 \mathrm{ml} / \mathrm{kg}$.bw DMSO.

STND: Normoglycaemic rats received $500 \mu \mathrm{g} / \mathrm{kg} . \mathrm{bw}$ of standard drug glibenclimide.

MODM 1: Normoglycaemic rats received $1.5 \mathrm{ml} / \mathrm{kg} . \mathrm{bw}$ of MODM

MODM 2: Normoglycaemic rats received $2.0 \mathrm{ml} / \mathrm{kg} . \mathrm{bw}$ of MODM

MODM 3: Normoglycaemic rats received $2.5 \mathrm{ml} / \mathrm{kg} . b w$ of MODM

2.2.7 Hypoglycaemic effects of petroleum ether oil extract of Moringa oleifera seed (PEEMO) on normoglycaemic rats: The rats were divided into 5 groups comprising of 3 animals each $(n=3)$.

CNT: Normoglycaemic rats received $2.5 \mathrm{ml} / \mathrm{kg}$.bw DMSO orally.

STND: Normoglycaemic rats received $500 \mu \mathrm{g} / \mathrm{kg} . \mathrm{bw}$ of standard drug glibenclimide orally.

MOPE 1: Normoglycaemic rats received $1.5 \mathrm{ml} / \mathrm{kg} . \mathrm{bw}$ of MOPE

MOPE 2: Normoglycaemic rats received 2.0 $\mathrm{ml} / \mathrm{kg} . \mathrm{bw}$ of MOPE

MOPE 3: Normoglycaemic rats received $2.5 \mathrm{ml} / \mathrm{kg} . \mathrm{bw}$ of MOPE

\subsubsection{Statistical Analysis.}

Data obtained are expressed as mean \pm SEM the analysis was done by using student T-test or analysis of variance (ANOVA) followed by Post hoc Duncan multiple comparisons test, using SPSS 16.00 version. The tests results with $P$ values $<0.05$ were taken to be statistical significance. 


\subsection{Results}

\section{Results And Discussions}

3.1.1 Oil yield from Moringa oleifera Lam seed: The percentage oil yield obtained from Moringa oleifera Seed using petroleum ether and dichloromethane are presented in table 1.There is significant difference in oil yield and the oil obtained are $37.29 \%$ and $34.43 \%$ from petroleum ether and dichloromethane respectively.

Table 1: Petroleum ether and dichloromethane oil yield oil yield from Moringa oleifera Lam seed

\begin{tabular}{ll} 
Solvent Used & Oil Yield (\%) \\
\hline PE & $37.29 \pm 0.40^{* *}$ \\
DCM & $34.43 \pm 0.34^{* *}$ \\
\hline
\end{tabular}

Values are Means of triplicates \pm Standard Error Mean (SEM). ${ }^{* *} \mathrm{P} \leq 0.01 \mathrm{~T}$-Test 2 tailed

Key: PE: Petroleum Ether, DCM: Dichloromethane

Table 2: Acute toxicity test

\begin{tabular}{|c|c|c|c|c|c|}
\hline \multirow[t]{2}{*}{ Group D } & Dose (5ml/kg.bw) & \multicolumn{2}{|c|}{ Toxicity Profiles } & \multirow[b]{2}{*}{ Mortality } & \\
\hline & Behavioural profile & Autonomic Profile & Neurological profile & & \\
\hline PEEMO & Normal & Normal & & rmal & Nil \\
\hline DCMMO & Normal & Normal & & rmal & Nil \\
\hline
\end{tabular}

Key:

PEEMO: Petroleum ether oil extract of Moringa oleifera seed

DCMMO: Dichloromethane oil extract of Moringa oleifera seed

3.1.2 Hypoglycaemic effects of petroleum ether oil extract of Moringa oleifera seed (PEEMO): The hypoglycaemic effects of petroleum ether oil extract of Moringa oleifera seeds (PEEMO) in normoglycaemic rat are presented in figure 1.There is significant increase at $\mathrm{P} \leq 0.05$ in glucose level at $30 \mathrm{mins}$ in the entire group except in the control group that shows significant decrease in glucose level. At 60mins the glucose level was reduced compare to that of $30 \mathrm{mins}$ but statistically, no significant difference between the entire groups at this period. Likewise there is significant reduction at $\mathrm{P} \leq 0.05$ in glucose level of the entire groups at $120 \mathrm{mins}$.

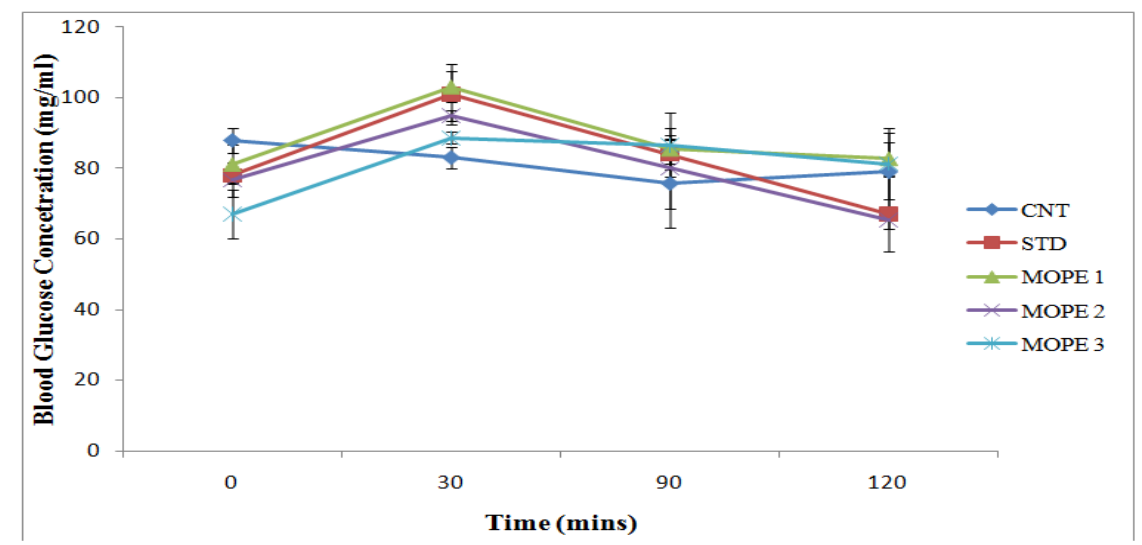

Figure 1: Hypoglycaemic effects of petroleum ether oil extract of Moringa oleifera Lam seed

Key:

CNT: Normoglycaemic rats received $2.5 \mathrm{ml} / \mathrm{kg} . \mathrm{bw}$ DMSO orally.

STND: Normoglycaemic rats received $500 \mu \mathrm{g} / \mathrm{kg}$.bw of standard drug glibenclimide orally.

MOPE 1: Normoglycaemic rats received $1.5 \mathrm{ml} / \mathrm{kg} . \mathrm{bw}$ of MOPE

MOPE 2: Normoglycaemic rats received $2.0 \mathrm{ml} / \mathrm{kg}$.bw of MOPE

MOPE 3: Normoglycaemic rats received $2.5 \mathrm{ml} / \mathrm{kg} . \mathrm{bw}$ of MOPE 
3.1.3 Hypoglycaemic effects of dichloromethane oil extract of Moringa oleifera seed (MODM): Hypoglycaemic effects of MODM on normoglycaemic rat are presented in figure 2. There is significant increase in glucose level at 30mins between all the groups except the control group that shows significant reduction in blood glucose. At $60 \mathrm{mins}$, the glucose level reduced compared to that of $30 \mathrm{mins}$ but no significant difference statistically between the entire groups at this period. There is significant reduction in glucose level of the entire groups at $\mathrm{P}<0.05$ at $120 \mathrm{mins}$.

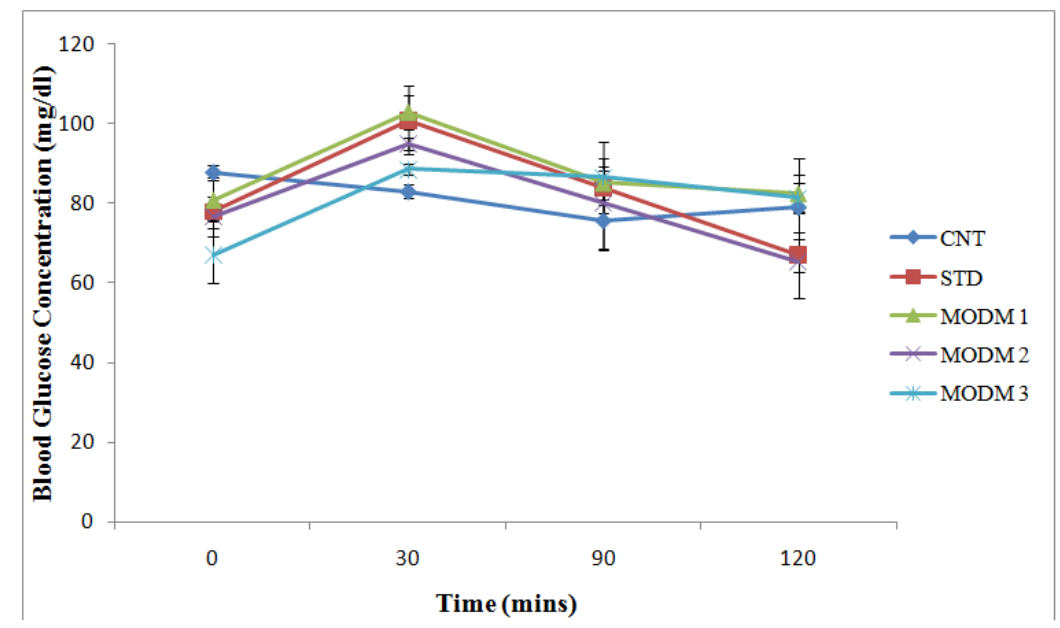

Key:

Figure 2: Hypoglycaemic effects of dichloromethane oil extract of Moringa oleifera Lam seed

CNT: Normoglycaemic rats received $2.5 \mathrm{ml} / \mathrm{kg}$.bw DMSO.

STND: Normoglycaemic rats received $500 \mu \mathrm{g} / \mathrm{kg}$. bw of standard drug glibenclimide.

MODM 1: Normoglycaemic rats received $1.5 \mathrm{ml} / \mathrm{kg} . \mathrm{bw}$ of MODM

MODM 2: Normoglycaemic rats received $2.0 \mathrm{ml} / \mathrm{kg} . \mathrm{bw}$ of MODM

MODM 3: Normoglycaemic rats received $2.5 \mathrm{ml} / \mathrm{kg} . \mathrm{bw}$ of MODM

\section{Discussion}

The significant difference in oil yield from Moringa oleifera seeds (Table 1) observed in petroleum ether and dichloromethane solvent (37.29 \pm 0.40 and $34.43 \pm 0.34$ respectively) was as a result difference in polarity of both solvent as also reported by García-Fayos et al. (2010).This observation also agreed with the previous report that the oil yield from Moringa oleifera seeds is between 25-41\% (Lalas and Tsaknis, 2002) and $20-45 \%$ (Cosge et al., 2007).

Significant increase in percentage glucose level in rats receiving the oil extract and standard drug at 30mins compared to their respective baseline glucose level, except the DMSO treated group (figure 1 and 2). This phenomenon of glucose increase at a time interval during the treatment of the animals might be as a result of induction of physiological stress due to the Introduction of exogenous compound into normal animal physiological systems which may cause certain biochemical and physiological and changes in man or animal (Rowsey et al., 2002). Exogenous compound is said to have capability of acting on the immune cell especially on mononuclear phagocytes one of the immune cell, hence endogenous pyrogens is induced (Bouwknercht et al. 2007). This particular pyrogens is known to belong to the group of proinflammatory cytokines,a neurotransmitter epinephrine is released when the cytokine signal to the brain and stimulate nerves of afferent (Hori et al., 2002). Nevertheless, the glucose level was brought down significantly ( $\mathrm{p}<0.05$ ) after 30mins (at 60 mins and 120 mins). However, only the glucose level of the experimental animals that received doses of $2.0 \mathrm{ml} / \mathrm{kg}$.bw MOPE and STND (figure 1) show significant decrease $(\mathrm{P}<0.05)$ at $120 \mathrm{mins}(65.33 \pm 2.52$ and $67.00 \pm 10.02$ ) which is $14.10 \%$ and $14.79 \%$ of their respective baseline glucose level. The same observation occurred in MODM as shown in figure 2. Only MODM $(1.5 \mathrm{ml}$ and $2.0 \mathrm{ml})$ and STND showed significant decrease in blood glucose level at $6.88 \%, 15.22 \%$ and $14.10 \%$ respectively to their baseline level at the end of 120 mins.

The mechanism at which the Moringa oleifera Lam. seed oil elicit its hypoglycaemic effect may be due to but not limited to sensitise peripheral tissue to increase blood glucose uptake or by assisting insulin secretion from pancreatic ß-cell (Sabu and Kuttan, 2002; Zereba et al., 2005). 


\section{Conclusion}

It can be concluded from this work that both petroleum ether and dichloromethane Moringa oleifera Lam seed oil extract at $2 \mathrm{ml} / \mathrm{kg}$ body weight have significant hypoglycaemic effects on normoglycaemic rat. Therefore, Moringa oleifera seeds oil can serve as a source of potential antidiabetic agent which can be an alternative to oral hypoglycemic agent or adjuvant.

\section{References}

[1]. M. Abdullah, G. Muhammad, and N. U. Abdulkadir, (2003). Medicinal and Economic Plants of Nupe Land (pp 276). Bida Nigeria: Jube-Evans Books and Publications.

[2]. Y. K. Adamu, A. S. Aderonke and E. O. Ogbadoyi (2010). Therapeutic effects of Annona senegalensis Pers stem bark extracts in experimental African Trypanosomiasis. Internationl Journal of Health Research, 3 (1), 45-49.

[3]. A.A. Adeneye, O. O.Amole and A. K. Adeneye (2006): Hypoglycemic and Hypocholesterolemic activities of the aqueous leaf and seed extract of Phyllanthus amarus in mice. Fitoterapia 77: 511-514.

[4]. J. A. Bouwknercht, B. Olivier and R. E. Paylor (2007). The stress-induced hyperthermia paradigm as a physiological animal model for anxiety: a review of pharmacological and genetic studies in the mouse. Neuroscience and Behavior, 31 (1), 41-59.

[5]. D. N. Calistus and C. O. Vincent (2011). Picralima nitida seed oil in hypoglycemic activity. Journal of Advanced Pharmacy Education \& Research, 2, 147-153.

[6]. L. A. Cheng-Tzu, W. A. Pei-Linn, L. A. Chong-Kuei, H. A. Hunry, and S. B. Lee-Yan, (2006). Antidiabetic effect of garlic oil but not diallyl disulfide in rats with streptozotocin-induced diabetes, Food and Chemical Toxicology, 44 (8), 1377-1384.

[7]. B. Cosge, B. Gurbuz and M. Kiralan (2007). Oil content and fatty acid composition of some (Carthamus Tinctorius L.) varieties sown in spring and winter. International Journal of Engineering Science, $\quad \mathbf{1}, 11-15$.

[8]. B. García-Fayos, J. M. Arnal, G. Verdul, and A. Saurí (2010). Study of Moringa Oleifera oil extraction and its influence in primary coagulant activity for drinking water treatment. International Conference on Food Innovation.

[9]. T. Hori, T. Katafuchi, K. Ota, T. Matsuda, T. Oka, and K. Oka (2002). Evidence for the Involvement of AV3V in the circulating ILIB to brain communication. Journal of Thermal Biology, 25, 29-33.

[10]. D. Jaiswal, R. P. Kumar, A. Kumar, S. Mehta, and G. Watal, (2009). Effect of Moringa oleifera Lam. leaves aqueous extract therapy on hyperglycemic rats. Journal of Ethnopharmacology, 123, 392-396.

[11]. H. King, R.E. Albert and W.H. Herman (1998): Global Burden of Diabetes 1995 - 2025: Prevalence, Numerical estimates and Projections. Diabetes Care 21(9): 1414-1431.

[12]. S. Mahadevappa, R. Arunchand, and K. Farhath (2011). Anti-diabetic effects of cold and hot extracted virgin coconut oil. Journal of Diabetes Mellitus, 1(4), 118-123.

[13]. R. Mohtashami, M. Amini, H. H. Fallah, M. Ghamarchehre, Z. Sadeqhi, R. Hajiagaee and H. A. Fallah, (2011). Blood glucose lowering effects of Nigella sativa L. seeds oil in healthy volunteers: A Randomized, Double-Blind, Placebo-Controlled Clinical Trial. Journal of Medicinal Plant, 10, 39.

[14]. Organisation for Economic Co-operation and Development (2008). Guideline for the test of chemicals. guidance document on acute oral toxicity. Enviromental health and safety monograph series on testing and assessment, OECD/OCDE, 425, p2.

[15]. R. Paliwal, V. Sharma and Pracheta, (2011). A review on horse radish tree (Moringa oleifera): A multipurpose tree with high economic and commercial importance. Asian Journal of Biotechnolology, 3, 1317-328.

[16]. R. Parivash, K. Najmeh, A. Sedigheh, and S. Mahbubeh, (2011). Anti-diabetic effects of walnut oil on alloxan-induced diabetic rats african. Journal of Pharmacy and Pharmacology. 5(24), 2655-2661.

[17]. P. J. Rowsey, Y. Yang and C. J. Gordon, (2002). Peripheral cholinergic pathway modulates hyperthermia induced by stress in rats exposed to open field stress. Journal of Applied Physiology, 92, 789-794.

[18]. R. R. Schippers, (2000). African Indigenous Vegetables: An overview of the cultivated species. Natural Resources Institute/ACPEU Technical Certre for Agricultureal and RuralCooperation (pp122-123) Chathan, UK.

[19]. M. C Sabu and R. Kuttan (2002). Antidiabetic activity of medicinal plants and its relationship with their antioxidant property. Journal of Ethnopharmacology, 81,155-160.

[20]. G. Zareba, N. Seriadell, R. Castaner, S. L. Davies, J. Prous and N. Mealy (2005). Phytotherapies for diabetes. Drug Fut, 30, 12531282. 